Article history:

Received: 15 January 2020;

Revised: 31 January 2020;

Accepted: 5 February 2020;

Available online: 15 February 2020

\title{
Momentum Imlek: Preferensi Konsumen Untuk Berbelanja Di Kawasan Kuliner Pasar Lama Tangerang
}

\author{
Fidellis Wato Tholok ${ }^{1}$ \\ Universitas Buddhi Dharma \\ fidelljst@gmail.com
}

\begin{abstract}
Abstrak
Hari Raya Imlek atau yang biasa dikenal sebagai festival musim semi merupakan saat yang paling ditunggu-tunggu kedatangannya tidak hanya oleh masyarakat yang termasuk dalam keturunan Tion Hoa di Indonesia, tetapi juga oleh para pedagang bahkan pebisnis secara global, atsmofer Imlek yang dominan diwarnai dengan warna merah ini semakin membuat meriah akan makna yang terkandung didalam Hari Raya Imlek itu sendiri. Dengan adanya momentum Imlek, budaya berbelanja akan semakin meningkat melebihi dari hari biasanya. Bagi para pedagang, Hari Raya Imlek dan layaknya Hari Raya lainnya akan melakukan sebuah tahapan pemasaran dimana para pedagang akan menyesuaikan dan merespons perilaku konsumen yang berubah dengan cepat. Para pedagang akan senantiasa beradaptasi untuk bersaing secara efektif dengan menerapkan program menarik seperti multi year transformation untuk memberikan peningkatan jangka panjang. Berdasarkan hal diatas, maka peneliti tertarik untuk membahas sebuah preferensi konsumen yang terbentuk saat momentum imlek untuk berbelanja di kawasan kuliner pasar lama Tangerang. Penelitian ini menggunakan analisis factor, dengan harapan dapat diketahui atribut dasar yang mendasari para konsumen secara garis besar alasan mereka untuk mengunjungi kawasan kuliner pasar lama Tangerang. Metode yang digunakan yaitu non probability sampling dan dalam menyebarkan kuesioner, penelitian ini pula menggunakan teknik gugus bertahap dengan harapan dapat mendapatkan jawaban yang beragam dari lima titik yang telah ditentukan. Sebanyak 169 responden dijadikan sampel dalam penelitian ini. Dalam pre test sebelum penyebaran kuesioner didapatkan hasil bahwa setidaknya ada enam atribut yang dijadikan dasar sebagai bahan preferensi utama para konsumen dalam mengunjungi Kawasan Kuliner Pasar Lama Tangerang dalam momentum Imlek yaitu Produk, Harga, Lokasi, Promosi, Atsmofer, dan Fasilitas Penunjang lainnya. Dari hasil uji analisis factor didapatkan hasil bahwa, setidaknya terdapat dua factor utama yang terbentuk, dimana dalam factor pertama, responden lebih dominan memilih variable produk $(76,9 \%)$, Promosi $(71,8 \%)$ dan fasilitas $(54,5 \%)$, dan dalam factor kedua, responden lebih dominan memilih berbelanja di kawasan kuliner pasar lama Tangerang berdasarkan variable Lokasi (79\%) dimana memang lokasi kawasan kuliner pasar lama Tangerang ini sangat mudah dijangkau lokasinya oleh kendaraan umum, Fasilitas $(41,6 \%)$ dan variable produk sebesar $(7,3 \%)$.
\end{abstract}

Kata Kunci: preferensi, konsumen

\section{Pendahuluan}

${ }^{1}$ Korespondensi: Fidellis Wato Tholok, Universitas Buddhi Dharma, Jl. Imam Bonjol. No. 41, Karawaci, Tangerang. fidelljst@gmail.com 
Tahun Baru Imlek yang identik dengan pernak-pernik bewarna merah asal dari Kebudayaan Tionghoa dan dikenal sebagai festival musim semi ini merupakan salah satu hari raya utama dari Agama Kong $\mathrm{Hu}$ Chu yang baru beberapa tahun ini telah menjadi salah satu Agama yang diakui Di Indonesia, atsmofer Imlek seperti halnya hari raya lainnya ternyata mampu mempunyai daya tarik yang demikian kuat bagi para masyarakat untuk meningkatkan intensitas berbelanja. Kenaikan intensitas untuk berbelanja ini mampu meningkatkan pendapatan para penjual, sehingga secara tidak langsung akan menumbuhkan nilai perekonomian dan berdampak positif secara umum pada tingkat pertumbuhan ekonomi bagi Negara Indonesia. Berdasarkan survey yang dilakukan (PT. Bank UOB Indonesia, 2017) menyimpulkan bahwa 40\% responden yang mewakili masyarakat terutama yang merayakan imlek berencana untuk berwisata baik kedalam maupun luar negeri untuk mengunjungi keluarga atau sahabat, lebih lanjut dalam survey tersebut menampilkan sebuah fenomena bahwa responden menggunakan 30\% dari rata-rata pengeluaran untuk Tahun Baru Imlek kepada kegiatan berbelanja dan wisata. selain ditujukan kepada kegiatan berbelanja dan wisata, budaya bagi ampao yang tidak lepas dari bagian Hari Raya Imlek ini juga menjadi sebuah tradisi yang sangat signifikan dari bagian kegiatan Imlek ini. Dikutip dari (Ariyanto, 2020) bahwa bisnis yang mempunyai platform marketplace online akan mengalami lonjakan transaksi belanja yang berbeda atsmofernya dibandingkan dengan hari raya lainnya. Sehingga dalam menghadapi datangnya Hari Raya Imlek pada umumnya para pedagang atau penjual akan melihat adanya peluang besar untuk mendapatkan keuntungan lebih daripada biasanya. Rangkaian promosi online dianggap sebagai salah satu cara jitu untuk menarik minat masyarakat untuk berbelanja, sehingga pada prakteknya para penjual akan sangat mungkin menghadapi adanya peningkatan transaksi berbelanja diawal sebelum hari raya imlek tiba. Para pedagang baik yang masih konvensional maupun sudah online akan berlomba-lomba untuk mengoptimalkan etalasenya agar lebih menarik minat para konsumen untuk berbelanja ditokonya. Dan pada akhirnya dalam lingkup pemasaran, kepuasan konsumen merupakan tujuan akhir yang mempunyai hubungan positif dengan peningkatan intensitas berbelanja yang ingin dicapai sehingga para penjual akan berusaha menjaga jalur komunikasi dengan baik.

Kawasan Kuliner Pasar Lama yang terletak di Jalan Cilame Pasar Lama, Kota Tangerang, merupakan titik magnet yang menjadi spot utama di Kota Tangerang. Melihat lokasi dan daya tarik masyarakat Kota Tangerang terhadap kawasan ini, membuat Pemerintah Kota Tangerang untuk melakukan penataan ulang dengan menambahkan beberapa titik kumpul yang memungkinkan masyarakat yang berkunjung dapat berkumpul di satu tempat sambil melihat pertunjukan seni musik yang silih berganti. (Silfa \& Dinda, 2019) menyatakan bahwa Kawasan Pasar Lama Tangerang telah menjadi salah satu destinasi wisata kuliner yang selalu ramai dikunjungi oleh para konsumen. Menjelang Hari Raya Imlek biasanya Kawasan Kuliner Pasar Lama ini akan menjadi pilihan utama bagi masyarakat Kota Tangerang untuk memenuhi kebutuhan menjelang Hari Raya Imlek. Melihat fenomena tersebut maka peneliti sangat tertarik untuk melihat preferensi konsumen untuk berbelanja di Kawasan Kuliner Pasar Lama dalam momentum imlek.

\section{Literature review}

Kota Tangerang merupakan salah satu kota yang berada dalam lingkup Provinsi Banten yang sedang mengalami perkembangan pesat menuju sebuah kota metropolitan, lokasi dan sumber daya yang ada di Kota Tangerang membuat Pemerintah Kota Tangerang melakukan beberapa pembenahan tata kota, dari taman-taman hingga pembangunan fasilitas kota lainnya seperti fasilitas hiburan berkeliling di Kota Tangerang dengan menggunakan bus beridentitas "Hey Tayo (Tangerang Ayo) dan "Jawara" (Jalan-Jalan Bersama Warga Tangerang), Komunitas masyarakat keturunan Tiong Hoa turut memberi warna kultur di system tatanan masyarakat Kota Tangerang, 
sehingga dalam momentum imlek sebagian besar masyarakat yang keturunan Tiong Hoa akan berbelanja di pusat perbelanjaan, dan bagi sebagian besar masyarakat keturunan Tiong Hoa yang bermukim di Kota Tangerang, akan mendatangi pusat perbelanjaan, untuk memenuhi kebutuhan Hari Raya Imlek, dan Kawasan Kuliner Pasar Lama Tangerang menjadi tempat utama yang dituju oleh sebagian masyarakat untuk memenuhi kebutuhannya, dan pada saat momentum imlek inilah Kawasan Kuliner Pasar Lama Kota Tangerang ini akan dibanjiri oleh lautan manusia yang bercampur menjadi satu di kawasan tersebut layaknya, pusat perbelanjaan glodok Jakarta. Pedagang di kawasan kuliner ini tidak hanya menjual kuliner tetapi juga produk lainnya. Hal inilah yang memunculkan factor atribut pada preferensi konsumen.

Factor atribut preferensi konsumen yang terbentuk akan menentukan seberapa besar atribut yang menentukan konsumen (masyarakat) untuk mendatangi Kawasan Kuliner Pasar Lama Tangerang, menurut (Sonny, 2019) menyatakan bahwa atribut merupakan daya tarik yang tercipta dari berbagai factor preferensi yang menjadi sebab dimana konsumen menyenangi suatu produk atau jasa, dimulai dari factor konsumen atau individu, kemudian pengaruh lingkungan, dan strategi pemasaran yang diterapkan oleh para penjual atau pedagang turut mempengaruhi atribut preferensi konsumen. Dengan kata lain (Phillip, 2003) atribut preferensi konsumen yang terbentuk menjadi dasar adanya perilaku konsumen dalam menentukan pembelian, hal inilah yang kemudian selaras dengan bauran pemasaran dimana ketertarikan masyarakat atas keinginan konsumen akan menjadi preferensi konsumen pada hal yang menjadi keinginan dan kebutuhan konsumen (Suhendar, 2019), preferensi konsumen merupakan alat yang cukup ampuh untuk menentukan keputusan konsumen dalam membeli sebuah produk atau jasa. Selain preferensi konsumen, alat lainnya yaitu kualitas, harga barang mapun kualitas pelayanannya dan alat lainnya yang dianggap obyektifitas dalam menentukan citra produk atau jasa.

Pada intinya preferensi konsumen ini bertujuan untuk melihat bagaimana konsumen mempunyai perilaku konsumsinya, permintaan, apa yang menetukan permintaan dan seterusnya yang terkait dengan "law of demand" didalam teori konsumen. Semua diawali dari preferensi konsumen dalam mengkonsumsi produk dan jasa yang dikenal dengan utility, utility merupakan nilai derajat kebahagiaan yang didapat konsumen ketika konsumen mengkonsumsi produk atau jasa, dengan kata lain, jika nilai derajat kebahagiaan konsumen yang didapatkan setelah mengkonsumsi barang atau jasa itu tinggi maka secara otomatis nilai utility sendiri akan meningkat, begitu juga dengan sebaliknya, sehingga dapat disimpulkan bahwa terdapat hubungan dengan nilai utility dengan jumlah barang atau jasa yang dikonsumsi (utility function), artinya utility merupakan sebuah gambaran tingkat kepuasan yang terukur yang didapat oleh konsumen dari mengkonsumsi barang dan jasa.

\section{Metode Penelitian}

Dalam penelitian ini, diawali sebelumnya dengan tahapan awal yaitu melakukan survey konsumen yang dilakukan pengujian (pre test) terlebih dahulu kepada 25 orang responden yang menyatakan kesediaannya untuk dapat dihubungi kembali. Survey pre test ini dilakukan dengan tujuan untuk merumuskan atribut yang sekiranya memiliki nilai utility yang paling dominan, dari hasil pre test tersebut disimpulkan bahwa setidaknya terdapat enam atribut yang memiliki kecendrungan muncul untuk dijadikan factor analisa, keenam atribut tersebut yaitu produk, harga, lokasi, promosi, atsmofer, dan fasilitas pendukung.

Setelah mendapatkan hasil dari survey yang dilakukan dalam rangka pre test selanjutnya dilakukan pengujian data dengan menggunakan analisa factor. Penentuan responden menggunakan metode non probability sampling dimana berdasarkan metode ini responden yang dipilih adalah orang-orang yang datang berkunjung ke Kawasan Kuliner Pasar Lama Tangerang 
untuk berbelanja kebutuhan hari raya Imlek. Populasi yang ditentukan mengikuti dasar pernyataan (Sugiyono, 2010) yang menyatakan ukuran sampel yang layak dalam penelitian adalah antara 30 sampai dengan 500, oleh karena itu dalam penelitian ini, peneliti mengambil 169 responden yang dijadikan sebagai sampel. Dan untuk mendapatkan hasil yang dapat mewakili seluruh populasi di Kawasan Kuliner Pasar Lama Tangerang, maka dilakukan pengambilan sampel responden menggunakan metode Gugus Bertahap (Joko \& Ratna, 2002), pada metode ini, penyebaran kuesioner dilakukan pada 5 titik atau lokasi yang menjadi bagian dari pusat keramaian di Kawasan Kuliner Pasar Lama Tangerang, yaitu Titik Tangga Jamban, Titik Kelenteng Boen Tek Bio, Titik Toko Es Buntin, Titik Toko Obat Ban An Tong, dan Titik Dermaga Apung (pinggiran kali cisadane). Jenis data yang digunakan dalam penelitian ini adalah data primer, metode yang digunakan dalam mengumpulkan data primer yaitu wawancara dan pengamatan langsung. Dari hasil penyebaran kuesioner tersebut, kini masuk ketahap kedua dalam penelitian ini yaitu melakukan pengolahan data. Untuk mencari besaran nilai utility factor-faktor yang bisa dijadikan sebagai dasar penelitian maka dilakukan dengan analisis factor yang terdapat didalam software SPSS versi 18, analisis factor ini peneliti anggap sesuai karena analisis ini memuat suatu informasi tentang pengelompkan variabel faktor dalam suatu penelitian, analisis ini bertujuan untuk menyaring variable mana yang paling dominan dari beberapa variable yang dipilih oleh peneliti. Hasil dari analisis factor inilah yang dugunakan sebagai pembeda komponen atau variable prioritas berdasarkan perangkingan yang ada. Analisis factor dalam penelitian ini juga dapat digunakan untuk mengetahui preferensi konsumen untuk datang ke Kawasan Kuliner Pasar Lama Tangerang dalam momentum Imlek, tentu preferensi yang digunakan berdasarkan hasil dari pre test sebelumnya yaitu kepada enam atribut yaitu produk, harga, lokasi, promosi, atsmofer, dan fasilitas penunjang lainnya. Untuk mengetahui preferensi konsumen terhadap enam atribut tersebut digunakan data rating dengan aturan penilaian mengkuti pembobotan pada skala likert lima butir.

\section{Hasil}

Karakteristik konsumen dalam penelitian ini terdapat dalam tabel 1 berikut yaitu:

Tabel 1. Persentase responden berdasarkan usia

\begin{tabular}{|c|c|}
\hline Kelompok usia & Persentase responden \% \\
\hline Dibawah 21 tahun & $12 \%$ \\
\hline $21-30$ tahun & $29 \%$ \\
\hline $31-40$ tahun & $34 \%$ \\
\hline Diatas 41 tahun & $25 \%$ \\
\hline
\end{tabular}

Responden survey dapat dibedakan menjadi responden pria dan wanita, bila dilihat dari jenis kelamin, hasil survey menunjukkan bahwa sebagian besar responden survey merupakan wanita yaitu sebesar $70 \%$ sedangkan persentase responden pria hanya sebesar 30\%. Dari tabel 1 juga dilihat adanya pengelompokan usia menjadi empat kelompok, yaitu usia dibawah 21 tahun, 21 sampai 30 tahun, 31 tahun sampai 40 tahun, dan usia diatas 41 tahun. Persentase responden terbesar terletak pada kelompok usia 31 sampai 40 tahun dengan tingkat persentase sebesar $34 \%$. Sedangkan tabel 2. Menggambarkan perbedaan tingkat pengeluaran berbelanja pada saat momentum imlek, jika 
Tabel 2. Persentase responden berdasarkan tingkat pengeluaran pada saat momentum imlek

\begin{tabular}{|c|c|}
\hline $\begin{array}{c}\text { Tingkat pengeluaran Rp. 000 } \\
\text { (ribuan) }\end{array}$ & $\begin{array}{c}\text { Persentase responden } \\
\%\end{array}$ \\
\hline Dibawah Rp. 2.000 & $30 \%$ \\
\hline Rp. 2.000 - Rp. 5.000 & $29 \%$ \\
\hline Diatas Rp. 5.000 & $41 \%$ \\
\hline
\end{tabular}

Tabel 3. KMO dan Bartlett's Test

KMO and Bartlett's Test

\begin{tabular}{|c|c|c|}
\hline \multicolumn{2}{|c|}{ Kaiser-Meyer-Olkin Measure of Sampling Adequacy. } & 686, \\
\hline \multirow[t]{3}{*}{ Bartlett's Test of Sphericity } & Approx. Chi-Square & 111,586 \\
\hline & df & 15 \\
\hline & Sig. & ,000 \\
\hline
\end{tabular}

Pada tabel 3 hasil output menunjukkan nilai Kaiser Meyer Olkin dan Bartlett's test diatas terlihat angka KMO Measure of sampling Adequacy (MSA) adalah 0.686. karena nilai 0.686 diatas 0.05 maka hal ini menunjukkan kecukupan dari sampel. Angka KMO dan Bartlett's test yang tampak pada nilai chi square sebesar 111.586 dengan nilai siginifikansi 0.000 . hal ini menunjukkan bahwa adanya korelasi antar variable dan layak untuk proses lebih lanjut. Selanjutnya untuk mengetahui variable mana yang dapat diproses lebih lanjut dan mana variable yang dikeluarkan dapat dilihat pada tabel anti-image matrices Tabel 4 dibawah ini.

Tabel 4. Anti-Image Matrices

Anti-image Matrices

\begin{tabular}{|ll|r|r|r|r|r|r|}
\hline & & Produk & Harga & Lokasi & Promosi & Atsmofer & Fasilitas \\
\hline Anti-image Covariance & Produk &, 699 &, 233 &, 058 &,- 227 &,- 071 &,- 109 \\
& Harga &, 233 &, 817 &, 001 &, 065 &,- 053 &, 125 \\
& Lokasi &, 058 &, 001 &, 945 &, 052 &, 134 &,- 125 \\
& Promosi &,- 227 &, 065 &, 052 &, 756 &,- 175 &,- 064 \\
& Atsmofer &,- 071 &,- 053 &, 134 &,- 175 &, 860 &,- 120 \\
& Fasilitas &,- 109 &, 125 &,- 125 &,- 064 &,- 120 &, 866 \\
\hline Anti-image Correlation & Produk &, 679 &, 309 &, 071 &,- 313 &,- 091 &,- 140 \\
& Harga &, 309 &, 684 &, 001 &, 083 &,- 063 &, 149 \\
& Lokasi &, 071 &, 001 &, 551 &, 062 &, 149 &,- 138 \\
& Promosi &,- 313 &, 083 &, 062 &, 711 &,- 217 &,- 079 \\
& Atsmofer &,- 091 &,- 063 &, 149 &,- 217 &, 680 &,- 139 \\
& Fasilitas &,- 140 &, 149 &,- 138 &,- 079 &,- 139 &, 718 \\
\hline
\end{tabular}

pada tabel anti-image matrice diatas, khusus pada bagian (anti-image correlation) terlihat angka yang bertanda (a) yang menandakan besaran MSA atas sebuah variable. Variable produk 0.679, harga 0.684 , lokasi 0.551 , promosi 0.711 , atsmofer 0.680 , dan fasilitas 0.718 . nilai MSA masingmasing variable besarnya diatas 0.5 maka semua variable dapat dilakukan analisa lebih lanjut. 
Tabel 4. Communalities

Communalities

\begin{tabular}{|l|r|r|}
\hline & \multicolumn{1}{|c|}{ Initial } & Extraction \\
\hline Produk & 1,000 &, 597 \\
Harga & 1,000 &, 486 \\
Lokasi & 1,000 &, 669 \\
Promosi & 1,000 &, 535 \\
Atsmofer & 1,000 &, 463 \\
Fasilitas & 1,000 &, 470 \\
\hline
\end{tabular}

Pada tabel communalities diatas, variable produk besarntya 0.597 hal ini bearti sekitar 59,7\% varians dari variable produk dapat dijelaskan oleh factor yang terbentuk. Variable harga 0.486 dan hal ini bearti 48,6\% varian dari variable harga dapat dijelaskan oleh factor yang terbentuk, variable lokasi besarannya 0.669 atau sekitar $66,9 \%$ varian dari variable lokasi dapat dijelaskan oleh factor lokasi, variable promosi besarannya 0.535 hal ini bearti sekitar 53,5\% varians dari variable promosi dapat dijelaskan oleh factor pembentuk, variable atsmofer yang terasa sebesar 0.463 atau sekitar 46,3\% varians dari variable atsmofer dapat dijelaskan olef factor yang terbentuk, dan untuk fasilitas nilai extration yang terbentuk dari hasil tabel communalities yaitu sebesar 0.470 atau hanya sekitar $47 \%$ varians yang dapat dijelaskan oleh factor yang terbentuk, dan jika kita Tarik kesimpulan maka, semakin kecil nilai communalitiesnya bearti semakin lemah hubungannya dengan factor yang terbentuk.

Tabel 5. Total Variance Explained

Total Variance Explained

\begin{tabular}{|c|r|r|r|r|r|r|}
\hline Component & \multicolumn{3}{|c|}{ Initial Eigenvalues } & \multicolumn{2}{c|}{ Extraction Sums of Squared Loadings } \\
\cline { 2 - 7 } & \multicolumn{1}{|c|}{ Total } & $\begin{array}{c}\text { \% of } \\
\text { Variance }\end{array}$ & $\begin{array}{c}\text { Cumulative } \\
\%\end{array}$ & Total & $\begin{array}{c}\text { \% of } \\
\text { Variance }\end{array}$ & Cumulative \% \\
\hline 1 & 2,086 & 34,768 & 34,768 & 2,086 & 34,768 & 34,768 \\
2 & 1,133 & 18,890 & 53,658 & 1,133 & 18,890 & 53,658 \\
3 &, 904 & 15,069 & 68,727 & & & \\
4 &, 729 & 12,143 & 80,870 & & & \\
5 &, 625 & 10,422 & 91,292 & & & \\
6 &, 522 & 8,708 & 100,000 & & & \\
\hline
\end{tabular}

Pada tabel total variance explained diatas menunjukkan ada dua factor yang terbentuk dari 6 variabel yang dimasukkan. Masing-masing factor eigenvalue > 1. Factor 1 eigenvalue sebesar 2.086 dengan variance sebesar $34.768 \%$, factor 2 eigenvalue sebesar 1.133 dengan variance sebesar $18.890 \%$. nilai eigenvalue menggambarkan kepentingan relative masing-masing factor dalam menghitung varians dari 6 variabel yang dianalisis. Bila semua variable dijumlahkan bernilai 6 (sama dengan banyaknya variable), missalnya:

$2.086 / 6 \times 100 \%=34.76 \%$

$1.133 / 6 \times 100 \%=18.88 \%$

Total varians apabila dari 6 variabel diekstrak menjadi 2 faktor adalah $34.76 \%+18.88 \%=$ $53.64 \%$. besarnya varians yang mampu dijelaskan oleh factor baru yang terbentuk adalah $53.64 \%$ sedangkan sisanya $46.36 \%$ dijelaskan oleh factor lain yang tidak diteliti. 


\section{Tabel 6. Component Matrixa}

Component Matrixa

\begin{tabular}{|l|r|r|}
\hline \multirow{2}{*}{} & \multicolumn{2}{|c|}{ Component } \\
\cline { 2 - 3 } & 1 & \multicolumn{1}{c|}{2} \\
\hline Produk &, 769 &, 073 \\
Promosi &, 718 &,- 143 \\
Harga &,- 598 &,- 358 \\
Fasilitas &, 545 &, 416 \\
Atsmofer &, 529 &,- 428 \\
Lokasi &,- 213 &, 790 \\
\hline
\end{tabular}

Tabel 6 diatas merupakan hasil output yang menampilkan rotated component matrikx nilai loading dari tiap-tiap variable tersebut. Untuk variable produk, korelasi antara variable produk dengan factor 1 (0.769), factor 2 (0.073) hal ini dapat dikatakan bahwa variable produk masuk kedalam kelompok factor 1, karena korelasinya paling tinggi diantara factor lain. untuk variable promosi, korelasi antara variable promosi kedalam kelompk factor $1(0.718)$, factor $2(-0.143)$ hal ini dapat dikatakan bahwa variable promosi masuk kedalam kelompok factor 1 karena korelasinya paling tinggi diantara factor lain. untuk variable harga, korelasi antara variable harga kedalam kelompok 1 (-0.598), factor $2(-0.358)$ hal ini menandakan bahwa variable harga tidak masuk kedalam kedua factor utama dengan kata lain tidak terdapat korelasi antara factor 1 dan 2 . Untuk variable fasilitas, korelasi antara variable kedalam kelompok 1 (0.545) dan factor $2(0.416)$ hal ini menandakan bahwa variable fasilitas masuk kedalam kelompok 1 karena korelasinya paling tinggi diantara factor lain. untuk variable atsmofer, korelasi antara variable atsmofer kedalam kelompok factor 1 (0.529) dan factor 2 (-0.428) hal ini menandakan bahwa variable atsmofer masuk kedalam kelompok 1 karena memiliki nilai korelasi yang tinggi. Dan untuk variable terakhir yaitu variable lokasi, korelasi antara variable kedalam kelompok factor 1 ($0.213)$ dan factor $2(0.790)$ hal ini menandakan bahwa variable lokasi masuk kedalam kelompok factor kedua karena memiliki nilai korelasi yang paling tinggi dibandingkan dengan factor 1 .

\section{Kesimpulan}

Berdasarkan hasil analisis diatas, dapat diambil beberapa kesimpulan bahwa Hari Raya Imlek atau festival musim semi juga dirayakan oleh sebagian masyarakat keturunan Tiong Hoa, dalam menyambut festival musim semi inilah, biasanya terdapat kenaikan atas kebutuhan menjelang hari raya imlek, sebagian pedagang atau penjual akan menangkap peluang emas ini untuk sebuah momentum emas dalam memasarkan produknya terkait barang-barang yang dibutuhkan, baik melalui online maupun secara konvensional. Dari analisa diatas pula dapat ditemukan bahwa preferensi konsumen untuk mengunjungi Kawasan Kuliner Pasar Lama Tangerang dalam menghadapi momentum imlek berada pada kategori setuju berdasarkan skala likert. Pola berbelanja di kawasan kuliner pasar lama ini seiring meningkat karena ada ada momentum imlek, dimana kawasan kuliner pasar lama Tangerang ini menjadi magnet tersendiri dalam menarik para konsumen (masyarakat) untuk mengunjungi kawasan ini yang menyediakan berbagai macam kebutuhan imlek.

Factor-faktor yang mempengaruhi intensitas para konsumen untuk datang berbelanja di kawasan kuliner pasar lama Tangerang antara lain factor ketersediaan atau keberagaman produk, harga, lokasi promosi atsmofer dan fasilitas penunjang. Karakteristik konsumen dapat dikelompokkan menjadi dua yaitu jenis kelamin, tingkat usia dan tingkat pengeluaran untuk kebutuhan Imlek. Hasil survey menunjukkan bahwa sebagian besar responden adalah wanita, berusia diatas 30 tahun dengan tingkat pengeluaran kebutuhan imlek diatas Rp. 5.000.000. dalam 
penelitian ini terdapat enam factor yang berhasil diolah berdasarkan pre test dimana enam factor ini mendasari pilihan konsumen untuk berbelanja di Kawasan Kuliner Pasar Lama Tangerang, secara berurutan yaitu produk, harga, lokasi, promosi, atsmofer, dan fasilitas penunjang. Dari hasil diatas pula dapat diketahui bahwa terbentuk dua factor dengan nilai eigenvalue diatas 1 , artinya terdapat dua kelompok responden secara garis besar yang memberikan pilihan untuk datang berbelanja di Kawasan Kuliner Pasar Lama Tangerang, dimana yang termasuk pada factor 1 adalah atribut yang memiliki tiga nilai rangking tertinggi yaitu atribut produk, promosi dan atsmofer yang dirasakan memiliki nilai utility tertinggi bagi preferensi konsumen, dan pada factor kedua berdasarkan urutan dari rangking tertinggi yaitu lokasi, fasilitas dan produk ini artinya pada kelompok kedua, responden menganggap bahwa ketiga atribut itulah yang mendasari mereka mendatangi kawasan kuliner pasar lama Tangerang untuk berbelanja di Momentum imlek.

\section{Daftar Referensi}

Ariyanto, D. (2020, Januari 9). Strategi Marketing Hadapi Tahun Baru Imlek 2020. Dipetik Januari 20, 2020, dari https://blog.sribu.com: https://blog.sribu.com/id/strategi-marketinghadapi-tahun-baru-imlek-2020/

Joko, H., \& Ratna, Y. A. (2002). Studi Perilaku Konsumen Dan Identifikasi Parameter Bakso Sapi Berdasarkan Preferensi Konsumen Di Wiliayah DKI Jakarta. Jurnal Teknol. dan Industri Pangan, 1-10.

Phillip, K. (2003). Manajemen Pemasaran. Jakarta: Indeks.

PT. Bank UOB Indonesia. (2017, Januari 27). Hasil Riset UOB: Orang RI Banyak Belanja dan Liburan Saat Imlek. Dipetik Januari 20, 2020, dari https://finance.detik.com: https://finance.detik.com/berita-ekonomi-bisnis/d-3407048/hasil-riset-uob-orang-ribanyak-belanja-dan-liburan-saat-imlek

Silfa, H. U., \& Dinda, R. (2019, Juni 30). Pasar Lama Tangerang, Ini 5 Kuliner Wajib yang Harus dicicipi. Dipetik Desember 15, 2019, dari https://www.suara.com: https://www.suara.com/lifestyle/2019/06/30/180000/pasar-lama-tangerang-ini-5-kulinerwajib-yang-harus-dicicipi

Sonny, S. (2019). Analisa Konjoin : Upaya Stimulus Konsumen Untuk Mengkonsumsi Cemilan Franchaise Makanan Jagung Daily Fresh “Lapak Cinsong” Di Vihara Dhamma Bhakti, Jawaringan, Kab-Tangerang. Eco-Buss, 1-7.

Sugiyono. (2010). Metode Penelitian Kuantitatif Kualitatif Dan R\&D. Bandung: CV. Alfabeta.

Suhendar, J. (2019). Melihat Preferensi Rukun Warga 13 Perumahan Villa Tangerang Indah dalam Memilih Ikan Konsumsi dengan Konsep Single Target dalam Pemasaran. EcoBuss, 45-52. 